Max-Planck-Institut für demografische Forschung

Max Planck Institute for Demographic Research

Konrad-Zuse-Strasse $1 \cdot$ D-18057 Rostock · GERMANY

Tel +49 (0) 3812081 - 0; Fax +49 (0) 3812081 - 202;

http://www.demogr.mpg.de

MPIDR WORKING PAPER WP 2008-024

OCTOBER 2008

\title{
Close kin influences on fertility behavior
}

\author{
Robert White \\ Laura Bernardi (bernardi@demogr.mpg.de)
}

(C) Copyright is held by the authors.

Working papers of the Max Planck Institute for Demographic Research receive only limited review. Views or opinions expressed in working papers are attributable to the authors and do not necessarily reflect those of the Institute. 


\section{Close Kin Influences on Fertility Behavior}

\section{Introduction}

The persistence of low fertility in Europe poses critical challenges to traditional explanations of fertility change. Conventional explanations of low fertility point to institutional factors such as labor market uncertainty, shifting returns to schooling and the relationships between both factors and entry into adulthood and marriage (Willis 1973; Becker 1981). Declines in economic outlook and delays in the traditional gateways to childbirth are tied to postponements in childbirth as well as falling rates of total fertility. Yet, fertility rates continue to lag behind gains in income, job expansion and alternate measures of economic growth (Ahn and Mira 2002, Engelhardt et al 2004). There is also increasing evidence that entry into marriage is of diminishing importance as a gateway for fertility. ${ }^{1}$ While there is emerging consensus that postponement of childbirth presents the potential for recovering an important share of foregone births (e.g., Lutz et al 2003, Sobotka 2004, Billari et al., 2006), this demographic solution to low fertility provides few insights into the pathways to low fertility.

Changing ideals of self and family pose an alternate set of forces affecting both the timing and magnitude of fertility. Individual ideals concerning career trajectories, family configurations and living arrangements as well as specific expectations for fertility timing and optimal family size present widely diverging consequences for fertility outcomes. Such ideals have long been part of historical accounts of changing fertility. Notestein's (1945) description of the demographic transition provided an early account in which changing social values were central to the onset of fertility decline. Hajnal (1965) pointed to cultural variation across Europe that corresponded with differences in family size, age at marriage and marriage rates to account for regional patterns in fertility outcomes. Both accounts may be credited with creating an enduring role for cultural values in the subsequent research concerning fertility change. Yet, it is only in the recent work concerning social networks and fertility outcomes that cultural values

\footnotetext{
${ }^{1}$ See Kohler et al. (2006) for a review.
} 
have become the focus in empirical analyses of fertility change. This growing area of research emphasizes empirical estimates of the effects from social interactions within networks of relationships on individual fertility. To the extent that cultural values are reflected in these influences, estimates of these effects offer insights into the importance of ideals for fertility.

We examine the effects of social interactions within kinships on individual fertility. We hypothesize that kin influences on fertility behaviors are a consequence of socialization processes which reflect the ideals held within kinships. Such processes may include social learning or social control among kin members with respect to kin behavioral norms in fertility timing, family size, living arrangements and other factors which are common among the proximate determinants of fertility. We adopt the unique genealogies dataset of the Kinship and Social Security project to assess the degree to which family structure may reflect such intrafamily influences on fertility outcomes. Sibship size and sibling gender distribution are adopted as measures of family structure. We are particularly interested in the relationship between the distributions of fertility outcomes across kin and individual fertility outcomes. While correlations between parents' and children's fertility have a long tradition in fertility studies (Pullum and Wolf 1991, Lyngstadt and Prskawetz 2006, Steenhof and Liefbroer 2008), we emphasize comparisons between inter-generational correlations and sibling correlations in fertility. The availability of socioeconomic measures in the KASS data also allows estimating correlations that account for an important set of covariates which has often been absent in larger studies of inter-generational correlations using registry data.

We proceed in Section two by outlining theories of social interactions and efforts to empirically estimate their consequences for fertility decline. Section three then describes the data and methods for estimating family influences. Descriptive statistics are outlined in Section 4. Section 5 is devoted to the main results with which we make inferences about family influences.

\section{Social interaction with kin and fertility}




\section{Social interaction in the first and second demographic transition}

Beginning with Notestein's (1945) formulation of the demographic transition, the relevance of cultural ideals as determinants of fertility behavior has been long recognized in demography. The observed close correspondence between variations in fertility outcomes and cultural clusters has been interpreted as evidence of the importance of changes in cultural values in historical fertility decline (Cleland 1985, Cleland and Wilson 1987, van de Walle and Knodel 1980, Rehrer 1998). In particular, an important part of the explanation for the rapid onset of fertility decline across Europe between 1880 and 1910 was a diffusion of new ideals that favored lower fertility and shifting gender roles (Coale 1975, Caldwell 1976). Changing cultural ideals are also emphasized in accounts of the fertility change that characterized the second demographic transition (van de Kaa 1987, Lesthaeghe and Surkyn 1988, Szreter 1993, Hirschman 1994, Kirk 1996). In this case, the increasing importance of individuality and autonomy occurred in conflict with contemporary ideals of family formation and ultimately gave rise to increases in age at first birth across Europe.

Despite the importance of ideals in these accounts, only the more recent research concerning social networks has offered an empirical framework for studying such influences in fertility change. Individual social interactions are a necessary condition for the effects of changing ideals on fertility outcomes. Exchanges of information and the exposure to new behaviors or efforts at social control may only occur through social interactions. While surveys are rarely able to reliably measure the content of these interactions, it is often feasible to collect data on the identity of family and friends. For this reason, efforts to estimate the effects of social interactions emphasize the characteristics of the networks of social relationships which are defined by these reports. For instance, dense networks may speed the diffusion of changes in behaviors while network size may account for variances in fertility outcomes (Kohler et al 2001, 2002, Behrman et al. 2002). Both attributes may then give rise to an interdependency of individual fertility outcomes. This interdependency was first characterized as a diffusion of ideals and knowledge that emerged from communication and observation regarding fertility norms and the means for achieving desired fertility outcomes (Montgomery and Casterline 1993, 1996; Bongaarts and Watkins 1996). 
Efforts to estimate network effects on fertility outcomes have emphasized network effects on contraceptive knowledge and practice (e.g., Entwisle et al. 1996, Rosero-Bixby and Casterline 1994, Rutenberg and Watkins 1997, Watkins 2000, Kohler 2001, Berhman et al. 2002). Contraception practice offers a clear test for the effects of changes in information. Changes in contraception practices have also been central in accounts of changes in fertility timing in the second demographic transition (van de Kaa 1987). Given the potentially large effects of changing contraception practices for fertility outcomes, many of these accounts point to the density of networks to explain the pace of declining fertility (e.g., Kohler et al 2001, 2002, Berhman et al., 2002). There remain many difficulties measuring social networks and empirically identifying their effects on individual behaviors. Moreover, the relationship between any estimated network influences and the ideals which are held by network members of course cannot be observed. However, variation in network influences on individual behaviors remains highly suggestive of the uniqueness of network attributes and a novel strategy for inferring the effects of social interactions.

\section{Intra-family transmission of fertility}

This chapter examines the influences of social interactions among kin on fertility outcomes. Understanding kin influences on individual behaviors has been an important objective in many anthropological studies of social structure. Part of this work, reviewed elsewhere in this volume, emphasizes exchanges among kin of financial resources, labor and the broad set of exchanges associated with marriage. Such kin exchanges may be particularly consequential not only for important pathways to fertility, such as marriage and household formation, but also the economic calculus of decision-making in fertility. Micheli (2000) further underscores the importance of kin structure in the effects of exchanges on demographic outcomes: "the kinship dominance area is not homogeneous within itself: different patterns of social network organization are to be found in it. In the stem-family area, social support hinges upon a network of kin (consanguineous), whilst in the unstable Mediterranean area social support hinges upon an alliance primarily among different kindred units, than upon a network with many relatives-in-law" (p. 20). In this case, different household structures and family forms may correspond to different patterns of kin exchange that may in turn be consequential for fertility. 
Kin are also uniquely positioned to influence fertility through pathways less easily measured than exchanges. For instance, kin exert life long influences on individual preferences for fertility timing and family size. Given the modern rise of contraception use and commensurate decline in undesired fertility, individual preferences for fertility outcomes may play an increasingly important role in fertility trends. ${ }^{2}$ Families may also exert explicit control over courtship, marriage timing, sexual behaviors and other proximate determinants to fertility.

Demographic studies of kinship and individual outcomes have largely followed two traditions: the study of household registers and the analysis of genealogies. Both approaches face limitations in assessing the relationship between kinship and demographic outcomes. Studies based on household registers mostly account for kin ties to the extent that kin co-reside across households. They also rarely possess the genealogical depth which would enable making inferences about influences from more distantly related kin.

By comparison, studies based on genealogies rarely have adequate information about residential units. One notable exception is Campbell and Lee's (2008) historical study of Liaoning, China, which emphasizes the social organization of kin and its effect on demographic and economic outcomes. This study shows that, contrary to the early $20^{\text {th }}$ century in Europe (Hajnal 1982, Laslett 1988), there is little difference between the demographic consequences of economic crisis in areas characterized by simple conjugal family household from those in areas with extended households. The authors argue that relationships among the households of noncoresident kin, and particularly siblings, had been crucial in coping with economic adversity.

The recognition of the role of kinship systems in shaping demographic and social outcomes has recently moved beyond the household level to consider kinship ties between relatives living elsewhere by combining ethnographic and survey data with historical and register information. Bras and van Tillburg (2007) consider the importance of kin interactions across households and show that, after controlling for other determinants of kinship communication, kinship values prevalent in a given region have an effect on non-coresident siblings' relationships across the Netherlands. Murphy (2008) uses the International Social Survey dataset to assess the variation across countries in co-residence, residential proximity and the frequency

\footnotetext{
${ }^{2}$ Bongaarts (1997) reviews the shifts in contraceptive use and fertility preferences in low income countries.
} 
of interaction and support among primary and secondary kin. Such studies present new opportunities for examining kin influences in a range of demographic phenomena and particular promise for further assessing the ties between family structure and fertility

While the recent work in this literature more closely considers the effects of family structure on fertility, much of the evidence of family effects on fertility outcomes emerges from demographic studies of intergenerational correlates in fertility. There is a long record of correlations between mothers' and daughters' completed fertility in historical population studies (Pullum and Wolf 1991, Ruggles 1993, Axinn et al. 1994, Murphy 1999, Gagnon and Heyer 2001, Murphy and Wang 2001, Lyngstadt and Prskawetz, 2006, Steenhof and Liefbroer, 2008). ${ }^{3}$ These correlations range between 0.084 and 0.221 with the variation often related to the length of coresidence of parents and children. This seeming empirical regularity in intergenerational correlations in fertility may reflect stability in family influences amid the dramatic cultural changes of post-war Europe.

The historical emphasis in demographic studies on regional correlates with fertility outcomes also remains suggestive of family effects. Hajnal's (1965) emphasis on household organization among the cultural factors corresponding with differences in fertility outcomes points to a set attributes which may also vary across families and account for within region fertility variation. More recent evidence of regional variation in family attributes and fertility further points to the nature of family interactions. In the countries of Southern Europe, where interaction with kin is deemed to be strong, fertility declined later than elsewhere but at a very rapid pace, ultimately reaching unprecedented lowest low levels. Although there is evidence that the desire for children (measured by reports of the ideal number of children) in contemporary southern Europe is no lower than in many northern European countries (Bongaarts 2001, Goldstein et al. 2007), there is also evidence that births are delayed to older ages more intensively (Kohler et al. 2006). This shift in fertility timing distinguishes lowest low fertility in southern Europe as mainly due to foregone births of order higher than one. These differences in both the onset of fertility and subsequent total fertility may be due to the intensity of kin interactions which both delays the entry to parenthood and amplifies individual responses to

\footnotetext{
${ }^{3}$ Ruggles (1993) reports additional estimates of inter-generational fertility correlations in the literature dating to 1945.
} 
socioeconomic difficulties. Additional qualitative evidence that the structure of interpersonal interaction and communication can play a major role in individual understandings of fertility ideals and intentions is further suggestive of the importance of the intensity of kin interactions (Bernardi et al 2005, Bernardi 2003, Bernardi and Oppo 2008).

There remain unique methodological concerns with estimating family effects on individual fertility outcomes. Inherited fecundity raises the possibility for cumulative selection effects in fertility over generations (Pullum and Wolf 1991). Both fecundity and general health also present potentially important omitted variables in the identification of family social influences. Moreover, the family remains only one among many sources of competing influences on fertility behaviors. Stability over time in attributes of shared social settings which are not easily measured with survey data present additional omitted variables which likely bias estimates of correlated fertilities across generations. Extensive evidence of the importance of peer groups for early sexual behaviors and labor market experiences for fertility timing also present formidable challenges to family influences over different periods in the life course. Such non-familial influences are likely increasingly important in the contexts of the growing geographic mobility that is common across Europe.

Much of the evidence of correlates between family attributes and fertility outcomes has been interpreted as observational learning and social control within families which shapes the transmission of parental values and fertility preferences to children. While such explanations of family influence are readily extended to siblings and more distant kin, there has been only speculative rather than empirical consideration of their importance in demographic studies of fertility change (e.g., Pullum and Wolf 1991). The KASS sample provides a unique opportunity to closely consider these wider kinship effects in fertility outcomes.

\section{Data}

The unique nature of the KASS genealogical data allows constructing a dataset of related kin families which that are defined by a union of parents and their children. A given generation begins as the children of a union or partnership. In the current context we refer to such a union 
and its offspring as a family, regardless of the duration or nature of the partnership. When the children in these families reach child-bearing age themselves, we consider them also at risk for entering unions and treat them as eligible partners. As a consequence adults may then be distinguished as members of two such families - as children in their birth families and as parents when they produce offspring later on. Figure 1 illustrates how these different families may be constructed from a given genealogy. The parents in the family labeled 1 are children in families 2 and 5. Similarly, the parents in family 2 are children in families 3 and 4.

Defining such families for every genealogy in the KASS sample results in a large dataset of related families that is well-suited for studying fertility outcomes. In particular, such a families dataset allows defining kinship level measures of fertility and covariates which are commonly associated with fertility outcomes. For these measures, observations of individuals when they are children are included in such measures as kinship mean cumulative fertility, age at first birth and birth intervals. However, since their fertility outcomes as adults are the main interest in this analysis, their adult outcomes are excluded from these kinship level measures. Rather, these are the main outcomes of interest and constitute the individual observations in our analytic samples.

An important concern in constructing such a dataset is the quality of reports of family structure. Given that KASS genealogies are reported by a single kin member, the probability for misreports in family structure and kin individual characteristics increases with the number of degrees of distance from respondents. The possibility for measurement errors in age, union status and fertility are particularly worrisome given the central importance of these measures in fertility analysis. For this reason, the dataset of families is limited according to the combination of two principles: degree of kin distance from respondents and nature of the relationship with the respondent. We limit the dataset to include individuals within three degrees of kin distance from respondents. For example, kin members who are three degrees from the respondent and related to the respondents' parents are included, while kin members who are related to the respondent through a spouse are limited to within two degrees. In Figure 1, the respondent is identified as the male (triangle) parent in family 1 and his first cousins are included in the families of the respondent's aunts and uncles. The full set of individuals appearing in the family dataset as both 
children and parents includes the following: the respondent; parents' siblings; siblings; siblings' spouses; spouse; spouse's siblings; children; and, children's spouses. The corresponding children and parents of these families contribute the remaining members of the family dataset.

Item non-response poses another potentially serious set of concerns for model estimates of family effects on fertility outcomes. An additional set of procedures was undertaken to mitigate these effects by estimating a set of models for generating imputed values for missing items. Although values for a large set of variables were imputed in these procedures, we included only the imputed values for age in the final analysis. The full details of these procedures and the sample weights are detailed in the appendix.

The analytic sample includes birth cohorts of women 1928-1937 through 1978-1987. We restrict our analysis to women for two reasons. First, our hypotheses are informed by a large body of theory that pertains to women's fertility preferences and expectations. Much of the associated empirical work similarly emphasizes samples of women. Second, to the extent that many of the characteristics which are typically associated with women's fertility outcomes may similarly account for fertility outcomes in our sample, we expect that our sample may then provide a credible dataset for exploring the effects of family structure.

The 1928-1937 birth cohorts are included on account of the large share of this cohort that is only one degree from ego. The age distribution of kin members included in the family dataset is due to the age structure of egos. In particular, $40 \%$ of the sample of egos are aged fifty years and older, resulting in a large proportion of observations in the families dataset that are aged seventy years and older but which are only one degree kin distance from egos. Given that measurement error in ages is likely to be the least among kin separated from egos by only one degree, these cohorts are included. The youngest birth cohort, 1978-1987, includes women aged 18-29 due to variation in the year of interview. The $55 \%$ of the resulting sample that is older than age 45 enables an analysis of completed fertility. 


\section{Fertility Trends in KASS}

We analysis the effects of family structure with two primary fertility outcomes: cumulative fertility and the age at first birth.

\section{Cumulative Fertility}

Table 4 reports the distribution of mean cumulative fertility across countries, cohorts and a set of socio-demographic characteristics which are often associated with fertility outcomes. Given the variation in the age distributions across the country samples, mean completed and cumulative fertility are reported by country. Variation in the age distributions across countries raises the potential for uneven inferences about fertility across countries. Figure 2 illustrates the variation in age distribution across the eight countries in the sample. The samples from Italy, Croatia and France are disproportionately older while Poland, Russia and Austria have the largest shares of younger birth cohorts.

Examining mean cumulative fertility by birth cohort in Table 4 illustrates the general decline in total fertility following World War II, despite the mean fertility indicator is in some cases (France and Italy for instance) lower than the one provided by nationally representative samples. It is important to note that the youngest birth cohorts (1968-1977 and 1978-1987) have not yet completed their fertility, resulting in underestimates of sample mean fertility. Figure 3 plots mean fertility by both country and cohort and confirm the consistent downward trend in mean cohort fertility across all countries (with the exception of Sweden). Due to the uncertainty in the calculation of mean cumulative cohort fertility for the two youngest birth cohorts, the series in Figure 3 includes only the four birth cohorts with completed fertility. Mean fertility in the 1928-1937 birth cohorts in Austria, Italy and Poland are approximately 2.5 and descend to $1.3,1.3$ and 1.6 respectively in the birth cohort 1958-1967.

Mean cohort fertility also varies in the expected manner by region, education, socioeconomic status and employment status. The final columns in Table 4 illustrate 
consistently negative relationships between cohort cumulative fertility and urban residence, university education, high socioeconomic status and full-time employment. These relationships also hold across all birth cohorts with the exception of socioeconomic status in the 1928 cohort. Mean cumulative fertility among these subpopulations by country also display consistent relationships. While the variables for residence, socioeconomic status and employment status each reflect individual attributes at the time of the survey rather than childbirth, the consistency of the relationships between these covariates and fertility with the expected determinants of fertility suggest that there may be sufficient temporal correlation in these measures to incorporate them into an analysis of the effects of family structure.

Adding a set of covariates to cross-country comparisons of fertility illustrates how differences in sample characteristics and in the effects of specific covariates mute some of these cross-country fertility differences. Rural region and education display particularly large effects. Table 5 reports estimates from Poisson models of the number of children ever born. Comparing models one and two shows how rural residence accounts for a large share of the fertility differences between France (the base country) and Austria in the cross-section. In contrast, whether due to their higher shares of rural populations or differences in rural fertility, Sweden displays larger fertility differences relative to France. Comparing models 1 and 3 similarly shows how the combined effect of smaller proportions of university degree recipients and the negative association between education and fertility amplify fertility differences in the crosssection between France and Austria and Germany while eliminating them between France and Sweden. Both sets of effects from regional residence and education are robust to including the full set of socioeconomic covariates (model four) and birth cohort indicators (model five).

Stratifying the sample by birth cohort illustrates the changes in these effects on cumulative fertility over time. Figure 4 illustrates the relative stability in the effect of rural residence and a significant change in the effect of partnership status over time. The points in the figure are the coefficient estimates from the saturated models in Table 5 and are estimated for each of the six birth cohorts. All coefficients display levels of significance at the level of $10 \%$ or less. In contrast to the stability in the effect of rural residence, partnership status displays a consistent increase across birth cohorts 1948-1957 and 1978-1987. The early part of these gains 
may partly reflect the rising importance of marriage for fertility outcomes during the post World War II period. Alternatively, the large increases in the two youngest birth cohorts may be due to the select nature of the individuals in these cohorts who have already given birth.

\section{Entry into Parenthood}

Table 6 reports the distribution of the mean age at first birth across successive birth cohorts for the set of covariates in Table 4. Mean age at first birth declines across birth cohorts before leveling or slightly increasing in the last two cohorts. While the decline in the mean age at first birth may appear inconsistent with trends in the postponement of entry in adulthood, three important attributes in the distribution of mean age at first birth shall be considered in order to see how this decline is consistent with trends in age at first birth across cohorts that have been reported elsewhere.

First, mean age at first birth in cohorts that have not yet completed fertility reflects select samples of individuals who have relatively higher probabilities of becoming parents than the childless individuals of their birth cohorts. That is, mean age at first birth is biased downward in younger birth cohorts (from 1965 onward) due to the absence of individuals who are postponing childbirth (right censoring). This selection effect almost certainly accounts for the positive slope at the beginning of the series of mean age at first birth shown in the graphs.

Second, cohort mean age at first birth varies with the sampled distribution of age across countries, reflecting different severity in this selection effect. Countries whose samples have age distributions skewed toward younger ages may have lower mean age at first births given similar age specific fertility rates. Figure 5 presents mean age at first birth by country and cohort. Here, it becomes clear that larger sample shares of youth in Austria and Poland in particular will draw mean age at first birth in these countries downward. A larger range of ten years is used here to define birth cohorts due to the paucity of individuals across five year birth cohorts in each country. 
Third, the general trend in mean cohort age at first birth within countries is broadly consistent with trends reported using the Council of Europe $(2001,2006)$ and Eurostat $(2002$, 2003, 2006, 2007). The general trend among these countries illustrates a decline in mean age at first birth from the earliest birth cohorts until the 1955-1964 birth cohorts followed by a leveling or slight increase among successive birth cohorts. Considering only the birth cohorts with completed fertility (roughly from the first birth cohort through cohort 1955-1964) eliminates selection effects and demonstrates more clearly a decline in age at first birth over time (with the exception of some outlying points e.g., Russia). It is important to again note that the reduced numbers of observations in countries with younger samples results in larger standard errors of the mean estimates.

While the large magnitude of the standard errors associated with the estimates in these trends gives pause to any extended cross-country interpretation of these cohort trends, it is important to note that they are consistent with a declining age at first birth across this set of successive birth cohorts. Frejka and Sardon's (2006) review of cohort fertility in six countries in Europe reported turning points in cohort mean age at first birth occurring among birth cohorts sometime between the late 1940s and 1960. Prior to this period, mean cohort age at first birth steadily declined from the early 1900s. Frejka and Sardon's (2006) report of Italy's series of mean cohort age at first birth in particular closely follows the Italian series in the KASS data for birth cohorts with completed fertility. These turning points are also consistent with the years identified as the periods during which average age of first birth began increasing in Europe (Kohler et al., 2002).

The general trend in mean cohort age at first birth across countries is broadly consistent with trends from the Council of Europe $(2001,2006)$ and Eurostat $(2002,2003,2006,2007)$. The general trend in age at first birth among the eight countries in our sample declines from the earliest birth cohorts until the 1955-1964 birth cohorts followed by an increase among successive birth cohorts. It is important to note that the reduced frequencies of observations in countries with relatively younger samples results in larger standard errors of the mean estimates. Table 6 reports these standard errors and the low frequencies of observations in many birth cohorts across countries. This effect is exacerbated by the variation in age distributions across countries. 
As noted above, relatively younger populations will have larger proportions of individuals with incomplete fertility. Thus, even holding age specific fertility constant across countries, the variation in the age distribution will result in lower mean age at first birth. The relatively younger samples from Austria and Poland may then account for the relatively lower mean age at first birth reported for the later cohorts in these countries.

Mean age at first birth across birth cohorts and across countries is generally consistent with the measures of mean cohort fertility reported above. Mean birth cohort age at first birth displays the U-shape over the post World War II period that is common in series of mean age at first birth. As in the figure reporting mean cohort fertility, the series for mean age at first birth is reported only for cohorts with completed fertility. Mean age at first birth in birth cohorts which have not yet completed fertility reflect select samples of individuals who have relatively higher probabilities of entry into adulthood than the zero parity members of their birth cohorts. For this reason, calculations of mean age at first birth are downward biased in the two youngest birth cohorts (from 1968 onward) in the absence of the individuals in these birth cohorts who are postponing entry into adulthood. This selection effect likely accounts for the leveling in mean age at first birth which is apparent in an extended series of mean age at first birth.

Table 6 also reports mean age at first birth by region, education, socioeconomic status and employment status aggregated across countries. These measures display the expected positive relationships between urban residence, university education and employment status and similarly display the decline and leveling trend across birth cohorts that is apparent in trends in the country specific means aggregated across these subpopulations.

These estimates of mean age at first birth are robust to the imputed values for individual age. Age at first birth may be particularly sensitive to the adoption of multiply imputed values for individual age due to its construction from the ages of both mothers and their first born children. Individual age is imputed for approximately $16 \%$ percent of mothers and their first born children in the resulting analytic sample. The pattern of missingness in age intervals among mothers and their first born children results in approximately $27 \%$ of observations relying on one or more multiply imputed values of individual age and thirteen percent relying on imputed values 
for both mother and first born child. This proportion of multiply imputed values for age does not systematically alter the reported trends in mean age at first birth. The differences in mean values across countries, cohorts and country-cohort combinations calculated from the analytic sample and a sample with only observed individual ages are not significantly different. While the declining frequencies of observations of mothers by both country and cohort requires the adoption of broader definitions of birth cohorts and the mean estimates by country and cohort maintain large standard errors, the lack of any apparent systematic difference in trends in age at first birth using the imputed age values suggests that the distributions of these observations are sufficiently similar to observed ages to incorporate in the analysis. The trend is also robust to including non-ego kin in the sample. In these cases, age at first birth is defined only for mothers who reported both their own birth year and their oldest child's (mother's and/or oldest sibling's) birth year. These observations should have the least amount of measurement error in age. Irrespective of the size of the age groups defining the birth cohorts, mean age at first birth continues to decline across successive birth cohorts. However, it is important to note the very wide range in confidence intervals for all cohorts of egos.

Table 7 reports estimated hazard ratios from Cox proportional hazards models of the rate of transition to first birth. The estimated models are comparable to the Poisson models estimated for cumulative fertility discussed above. As above, adding rural residence and university education attenuates differences between Poland and France in the rate of transition to first birth and illustrates the muted differences between Sweden and France in the cross-tabulations. Both effects are robust to the full set of covariates. The effect of partnership status is consistent with the effect on cumulative fertility, showing a large positive effect. While a more complete specification would account for the age of partnership, the nature of the partnership indicator and the poor quality of the age at union data prevent incorporating such a measure. The partnership variable is an indicator of whether the individual is in a marriage or co-resides with a child. The question in the survey instrument for collecting this information insufficiently specified the time frame and excluded co-residence without children, limiting the range of living arrangements measured by this variable. The high likelihood for substantial measurement error in respondents' reports of their kin's date of marriage and co-residence further complicates including a covariate for age of marriage. 
Estimates from stratifying the sample by birth cohorts are reported in Figure 6. As in the case of rural residence for cumulative fertility, the effects of both rural residence and education remain stable across birth cohorts. As expected, partnership status shows the largest effect and consistently increases across birth cohorts.

\section{Family Structure and Fertility}

In the absence of observations of interactions among family members, we infer family influences by examining variations in fertility outcomes across different family structures. We hypothesize that correlations between family structure and fertility outcomes partly reflect the influences of the unique intra-family social interactions which arise in different family structures. Sibship size and sibship gender distribution are adopted to distinguish family structure. Sibship size has clear consequences for the intensity of intra-family interactions and the commensurate opportunities for reinforcing or challenging family behavioral norms. We estimate intergenerational correlations in cumulative fertility to capture the effects of this measure of family structure. Sibship gender distribution may also affect interactions regarding sexual behaviors, contraception, expectations for life course transitions and desired fertility. If sisters and brothers experience different interactions with respect to these issues, then those differences may be reflected in different fertility outcomes.

We first examine bivariate correlations in cumulative fertility outcomes among parents and their children. Table 8 reports bivariate correlations between women's cumulative fertility and their own sibship across countries and cohorts. The estimated correlations vary across both sample countries and cohorts and are significant for all countries but Sweden. These correlations are suggestive of the transmission of family size across generations. Table 9 reports bivariate correlations between reference individuals' cumulative fertility and that of their sibship. With the exception of Poland, all of the reported effects in Table 9 are significant. However, disaggregating these correlations by sex illustrates how siblings' influences on individual fertility may vary between sisters and brothers. The second and third columns of Table 9 report the disaggregated sibling fertility correlations and demonstrate the variation between brothers and 
sisters across countries. Sisters' correlations are significantly different and greater in Germany, France and Poland. All the remaining differences in the correlations by gender are not significant. The bottom panel of Table 9 reports sibling correlations across cohorts and shows that sisters' correlations are greater and significantly different than sisters' correlations with their brothers' fertility for the 1948 and 1958 birth cohorts.

Models of both cumulative fertility and entry into parenthood are estimated to assess the importance of kin influence on fertility. All models include controls for age and age squared to account for changes in fertility with age that will occur in birth cohorts with incomplete fertility. While partnership status is strongly associated with fertility outcomes, marriage duration is not included out of concern for the wide scope of measurement error in this variable attributable to the survey design. The estimated models only partly account for the possible effects from unobserved heterogeneity in fertility behaviors. All model estimates are robust to clustering within kinships. However, the bias in coefficient estimates that may arise from such unobserved factors is not taken into account. For instance the association of mothers' and daughters' late age at first birth may reflect correlated sub fecundity as well as the effect of socialization.

Closer scrutiny of the bivariate relationship between sibship size and the number of children born demonstrates that the KASS sample does not provide supportive evidence for this measure of inter-generational transmission in fertility. Table 10 reports estimates from poisson models of the count of children born to the date of interview since the age at first risk for pregnancy (15 years). Model 1 provides an alternative measure of the bivariate relationship adding only field site indicators (not shown). One of the benefits of the KASS sample is the availability of socioeconomic status assessments by respondents of all kin members. As may be seen in Model 2, including these assessments does not change the significance or magnitude of the sibship coefficient. However, partnership status completely attenuates the effect of sibship, raising the potential importance of age at marriage and fertility outcomes. The estimates of sibship effects in a cox proportional hazard model for the risk of first childbirth similarly do not produce supportive evidence for the importance of sibship size. 
While the other measures of family structure, including birth order, do not demonstrate any significant for fertility outcomes, age differences among siblings correlate with the rate of entry into parenthood. Table 11 shows how women separated by a larger number of years from their nearest older sibling are at greater risk for first childbirth. Models 2 and 3 demonstrate the robustness of these estimates to additional controls for age, a polynomial in age, sibship and the additional socio-demographic characteristics outlined in Table 4.

Parents' fertility characteristics do not display any importance in individual fertility outcomes. Many of the measures of mother's fertility characteristics demonstrated significant correlations with fertility in the presence of country controls. However, these variables, including mother's fertility age range, birth order and sibship are fully attenuated when accounting for partnership status, rural residence and socioeconomic status.

The estimates suggest that a large part of familial influence on fertility behavior may be measured with siblings' fertility outcomes. The estimated bivariate correlations of cumulative fertility among siblings detailed in Table 9 prove robust to the addition of the full set of sociodemographic controls. Table 12 illustrates the relative stability in the correlation of siblings' mean fertility with cumulative fertility upon the addition of sibship, age difference and the remaining set of socio-demographic covariates.

The measure of aggregate siblings' mean fertility conceals the possible differential effects from brothers' and sisters' fertility that were suggested in the bivariate correlations by sex. Table 13 reports the estimates of mean sibling fertility while accounting for the origin of any potential influences among siblings. To distinguish the effects of siblings by sex, the effects of average fertility are estimated among alternate sets of siblings. As above, Model 1 shows that mean fertility across all siblings is significant and positive. The effect of brothers' mean fertility is also significant when mean sibling fertility is not included (Model 2). However, when siblings' mean fertility effects are estimated that account for brothers' fertility, there is an increase in the aggregate siblings' effect and attenuation in the brothers' effect. This suggests that the large part of the effect from siblings' mean fertility behavior is driven by sister's behavior. Brothers' fertility alone is significant to the extent to which brothers' fertility is correlated with sisters' 
fertility, as shown in Table 9. However, across sample members with comparable levels of brothers' mean fertility, any increase in average fertility effects must come from either increases in outlier siblings' fertility or, more likely, increases in sisters' mean fertility. An alternative illustration of the sisters' effect may be shown by isolating the effect of brother's average fertility. By similarly holding sisters' average fertility constant, Model 5 shows that siblings' fertility is no longer significant.

This analysis was repeated by cohort to examine whether there might be any trends in siblings' effects. The small samples sizes of the cohorts resulting after limiting the sample to sibships of at least two with at one male and one female prevented any precise analysis. In larger, twenty year birth cohorts, the effects appeared to be largely driven by the 1948-1967 cohort. However, given the sample sizes and broad range of fertility behaviors possible in a twenty year birth cohort, it should be noted that these findings may suggest changes in the effects of sisters' and brothers' fertility over time.

\section{Conclusion}

To the extent that family influences on individual fertility may be reflected in correlated fertility outcomes, genealogical data provide a rich source of information for examining the scope of social influence in fertility change. By examining the relationship between measures of family structure, parents' fertility outcomes and siblings' fertility outcomes, we aim to assess the importance of inter-generational transmission of fertility behaviors and siblings' influences on fertility outcomes. We find limited evidence consistent with the inter-generational transmission of fertility behaviors. Including simple measures of individual socio-economic status and partnership status in our models fully accounts for intergenerational correlations in cumulative fertility.

By contrast, siblings' influences appear to constitute a large share of familial influences on fertility outcomes. Siblings' mean fertility is positively associated with own fertility, independent of sibship size and age differences among siblings. While siblings' cumulative fertility may influence one's own preferences for family size, it may also reveal new concerns for 
prospective parents with uncertain consequences for fertility behavior. Prospective parents may realize new costs that they attribute with children, or alternatively, they may become aware of new benefits, such as social support networks that are associated with offsetting the costs of having children. Just as the expected costs and rewards pertaining to future earnings has been shown to correlate with the timing of entry into motherhood (Liefbroer, 2005), siblings' fertility may then reveal to family members additional costs and rewards that are attributed to childbirth.

However, siblings' fertility effects on the timing of childbirth also depend on who in the family gives birth. The independent effect of sisters' fertility suggests distinct sets of influences among brothers and sisters on individual fertility. This could of course also reflect nonlinearities in the effects of siblings' fertility, whereby greater fertility among siblings increasingly offsets the effects from other influences that may in turn reduce the age of entry into parenthood, no matter which siblings are having children.

This chapter presents evidence of the possible importance of family structure for kin influences on individual fertility decision-making. The results are suggestive of gendered pathways of influence on fertility within kinships. It is important to note that these effects may be changing across cohorts. The cohort analysis finds variance in both significance and magnitude in the estimated effects across cohorts. While the constraints of the available data preclude any further inference about cohort effects, these effects are consistent with changes in the composition of social influences on fertility outcomes.

The interdependence of fertility among siblings raises the possibility of the cascading declines in fertility that network analysts emphasize in studies of the diffusion of contraceptive practices. In this case, the large number of possible pathways by which siblings may influence one another's fertility may increase the effective rate of changing fertility outcomes. Such kin influences may also pose important barriers to reversing trends toward later age at first birth and lower completed fertility. While any single individual in a kinship may deviate to earlier age at first birth or greater parity, the influences from their example still must compete with kinship wide prevalences in fertility outcomes. Far from the tipping point for reversing fertility trends, 
kin influences may then pose an important set of constraints to emerging from Europe's current low fertility regime. 


\section{References}

Ahn, N. and P. Mira 2002. "A note on the changing relationship between fertility and female employment rates in developed countries." Journal of Population Economics 15: 667682.

Axinn, W.G., M.E. Clarkberg and A. Thornton. 1994. "Family Influences on Family Size Preferences," Demography 31(19): 65-79.

Becker, G. S. 1981. A Treatise on the Family. Cambridge, MA: Harvard University Press.

Behrman, J.R., H.-P. Kohler and S. C. Watkins. 2002. "Social Networks and Changes in Contraceptive Use over Time: Evidence from a Longitudinal Study in Rural Kenya," Demography, 39(4):713-738.

Bernardi, L. 2003. "Channels of Social Influence on Reproduction," Population Research and Policy Review, 22: 527-555.

Bernardi, L., H. von der Lippe and S. Keim. 2005. "Mapping Social Influence on Fertility: A Mixed Method Approach to Data Collection,” MPIDR Working Paper WP-2005-015, Max Planck Institute for Demographic Research, Rostock.

Bernardi, L. and A. Oppo. 2008. "Female-centered Family Configurations and Fertility," in Widmer E. and R. Jallinoja (eds.), Beyond the Nuclear Family: Families in a Configurational Perspective, Peter Lang Editor: 175-202

Billari, F. C., H.-P. Kohler, G. Andersson and H. Lundström. 2006. "Approaching the Limit: Long-Term Trends in Late and Very Late Fertility." Population and Development Review 33(1):149-170.

Bongaarts, J. 1997. "Trends in unwanted childbearing in the developing world," Studies in Family Planning 28(4): 267-277.

Bongaarts, J. 2001. "Fertility and Reproductive Preferences in Post-Transitional Societies." Population and Development Review, 27: S260-S281.

Bongaarts, J. and S. Watkins. 1996. "Social interactions and contemporary fertility transitions." Population and Development Review, 22(4):639-682

Bras, H. and T. van Tilburg. 2007. "Kinship and Social Networks: A Regional Analysis of Sibling Relations in Twentieth-Century Netherlands." Journal of Family History, 32 (3):296-322.

Caldwell, John 1976. "Towards a Restatememt of Demographic Transition Theory." Population and Development Review, 2:321-366. 
Campbell, C. and J. Lee. 2008. "Kin Networks, Marriage, and Social Mobility in Late Imperial China Campbell and Lee." Social Science History, 32: 175-214.

Cleland, John. 1985. "Marital Fertility Decline in Developing Countries: Theories and Evidence." In Reproductive Change in Developing Countries: Insights from the World Fertility Survey, e. John Cleland and John Hobcraft. London: Oxford University Press, pp.223-252.

Cleland, John and Christopher Wilson. 1987. "Demand Theories of the Fertility Transition: an Iconoclastic View." Population Studies 41(1):5-30.

Coale, Ansley. 1975. “The Demographic Transition," in United Nations, The Population Debate: Dimensions and Perspectives, Vol.1.

Council of Europe. 2001. Recent Demographic Developments in Europe. Strasbourg: Council of Europe Publishing.

Council of Europe. 2006. Recent demographic developments in Europe 2005. Strasbourg: Council of Europe Publishing.

Daniels, M.J. and J. W. Hogan. 2008. Missing Data in Longitudinal Studies. Chapman Hall.

Engelhardt, H., T. Kögel, and A. Prskawetz. 2004. "Fertility and women's employment reconsidered: A macro-level time series analysis 1960-2000." Population Studies 58(1), 109-120.

Entwisle, B., R.R. Rindfuss, D.K. Guilkey, A. Chamratrithirong, S.R. Curran, and Y. Sawangdee. 1996. "Community and Contraceptive Choice in Rural Thailand: A Case Study of Nang Rong," Demography 33:1-11.

Eurostat. 2002. New Cronos database. Theme 3: Population and social conditions. Luxembourg: Office for Official Publications of European Communities.

Eurostat. 2003. New Cronos database. Theme 3: Population and social conditions. Luxembourg: Office for Official Publications of European Communities.

Eurostat. 2006. Population statistics. 2006 edition. Luxembourg: Office for Official Publications of European Communities.

Eurostat. 2007. Population and Social Conditions. Luxembourg: Office for Official Publications of European Communities.

Frejka, T. and J.-P. Sardon. 2006. "First birth trends in developed countries: A cohort analysis," Demographic Research, 15(6):147-180. 
Gagnon, A., and E. Heyer. 2001. "Intergenerational correlation of effective family size in early Quebec (Canada)." American Journal of Human Biology, 13(5):645-659.

Goldstein, J.R., W. Lutz, and M.-R. Testa. 2003. "The Emergence of Sub-Replacement Fertility Ideals in Europe," Population Research and Policy Review Policy Review, 22(5-6):479496.

Hajnal, J. 1965. "European marriage pattern in perspective." In D. V. Glass and D. E. Eversley (Eds.), Population in History: Essays in Historical Demography, pp. 101-143. Chicago, Illinois: Aldine Publishing Company.

Hajnal J. 1982. "Two Kinds of Pre-Industrial Household Formation System.” Population and Development Review, 8(3):449-94.

Hirschman, Charles 1994. "Why Fertility Changes.” Annual Review of Sociology 20:203-233.

Jonker, M. A. and van der Vaart, A. W. 2007. "Correcting missing-data bias in historical demography," Population Studies, 61:1, 99-113.

Kirk, Dudley. 1996. “A Demographic Transition Theory”Population Studies 50:361-387.

Kohler, H.-P. 2001. Fertility and Social Interactions: An Economic Perspective, Oxford: Oxford University Press.

Kohler, Hans-Peter, Jere R. Behrman, and Susan C. Watkins. 2001. "The Density of Social Networks and Fertility Decisions: Evidence from South Nyanza District Kenya." Demography, 38: 43-58

Kohler, H.-P., F.C. Billari and J.A. Ortega. 2002. "The Emergence of Lowest-Low Fertility in Europe during the 1990s," Population and Development Review, 28: 641-680.

Kohler, H.-P., F.C. Billari and J.A. Ortega. 2006. "Low Fertility in Europe: Causes, Implications and Policy Options." In F. R. Harris (Ed.), The Baby Bust: Who will do the Work? Who Will Pay the Taxes? Lanham, MD: Rowman \& Littlefield Publishers, pgs. 48-109.

Laslett, P. 1988. "Family, Kinship and Collectivity as Systems of Support in Pre-Industrial Europe: A Consideration of the 'nuclear-Hardship' Hypothesis." Continuity \& Change, 3(2): 153-175.

Lesthaeghe, R. and Surkyn, J., 1988. "Cultural dynamics and economic theories of fertility change," Population and Development Review, 14, 1-45.

Liefbroer, A.C. 2005. The Impact of Perceived Costs and Rewards of Childbearing on Entry into Parenthood: Evidence from a Panel Study," European Journal of Population, 21: 367391. 
Lutz, Wolfgang, Brian C. O’Neill, and Sergei Scherbov. 2003. "Europe's population at a turning point," Science 299: 1991-1992.

Lyngstadt and Prskawetz, 2006. “Do siblings' fertility histories influence each other?” Paper presented at the Population Association of America Annual Meetings, New York, NY.

Micheli, G. 2000. "Kinship, Family, and Social Network: The anthropological embedment of fertility change in Southern Europe." Demographic Research, 3 (13).

Montgomery, M. R. and J. B. Casterline. 1993. "The Diffusion of Fertility Control in Taiwan: Evidence from Pooled Cross-Section Time-Series Models.” Population Studies, 47: 457479.

Montgomery, M. R. and J. B. Casterline. 1996. "Social Learning, Social Influence, and New Models of Fertility." Population and Development Review, 22: S151-S175.

Murphy, M. 1999. "Is the relationship between fertility of parents and children really weak?" Social Biology, 46(1-2), 122-145.

Michael, M. 2008. "Variations in Kinship Networks Across Geographic and Social Space." Population and Development Review 34(1): 19-49

Murphy, M., and Wang, D. 2001. "Family-level continuities in childbearing in low-fertility societies." European Journal of Population, 17, 75-96.

Notestein, Frank. 1945. "Economic problems of population change." Proceedings of the Eighth International Conference of Agricultural Economists. London: Oxford University Press.

Pullum, T. and D. Wolf. 1991. "Correlations Between Frequencies of Kin.” Demography 28: 391-409.

Raghunathan, T. E., J. M. Lepkowski, J. H. van Hoewyk and P. Solenberger. 2001. “A multivariate technique for multiply imputing missing values using a sequence of regression models," Survey Methodology, 27, 85-95.

Reher, D. S. 1998. "Family ties in Western Europe: Persistent Contrasts," Population and Development Review, 24(2): 203-234.

Rosero-Bixby, L. and Casterline, J. B. 1994. "Interaction, Diffusion and Fertility Transition in Costa Rica,” Social Forces, 73: 435-462.

Rubin, D. B. 1976. "Inference and missing data." Biometrika, 63:581-592.

Rubin, D. B. 1987. Multiple imputation for nonresponse in surveys. New York: Wiley. 
Rubin, D. B. and R.J. Little, 2002. Statistical Analysis with Missing Data, 2nd edition. Hoboken, N.J.: Wiley-Interscience.

Ruggles, S. 1993. "Confessions of a Microsimulator - Problems in Modeling the Demography of Kinship," Historical Methods, 26(4): 161-169.

Rutenberg, N. and S.C. Watkins. 1997. "The Buzz Outside the Clinics: Conversations and Contraception in Nyanza Province, Kenya.” Studies in Family Planning 28:290-307.

Sobotka, T. 2004. "Is lowest-low fertility explained by the postponement of childbearing?" Population and Development Review, 30(2): 195-220.

Steenhof, L. and A.C. Liefbroer. 2008. "Intergenerational transmission of age at first birth in the Netherlands for birth cohorts born between 1935 and 1984: Evidence from municipal registers," Population Studies, 62(1): 69-84.

Szreter, S. 1993. "The idea of Demographic Transition and the study of fertility change: A critical intellectual history" Population and Development Review, 19(4):659-701.

Tanner, M. and W. Wong. 1987. "The calculation of posterior distributions by Data Augmentation (with discussion)." Journal of the American Statistical Association, 82, 528-550.

van Buuren S., H. C. Boshuizen and D. L. Knook. 1999. "Multiple imputation of missing blood pressure covariates in survival analysis." Statistics in Medicine, 18:681-694.

van de Kaa, D. J. 1987. "Europe's second demographic transition," Population Bulletin 42(1). Washington, DC: Population Reference Bureau.

van de Walle, Etienne and John Knodel.1980. "Europe's Fertility Trantisition: New Evidence and Lessons for Today's Developing World." Population Bulletin. 34(6):3-44. Washington, DC: Population Reference Bureau.

Watkins, S.C. 2000. "Local and Foreign Models of Reproduction in Nyanza Province, Kenya, 1930-1998." Population and Development Review 26:725-60.

Willis, R. J. 1973. "A new approach to the economic theory of fertility behaviour," Journal of Political Economy 81(2): 14-64. 


\section{Appendix 2. Figures and Tables}

Figure 1. Selecting Families within Three Degrees of Kinship

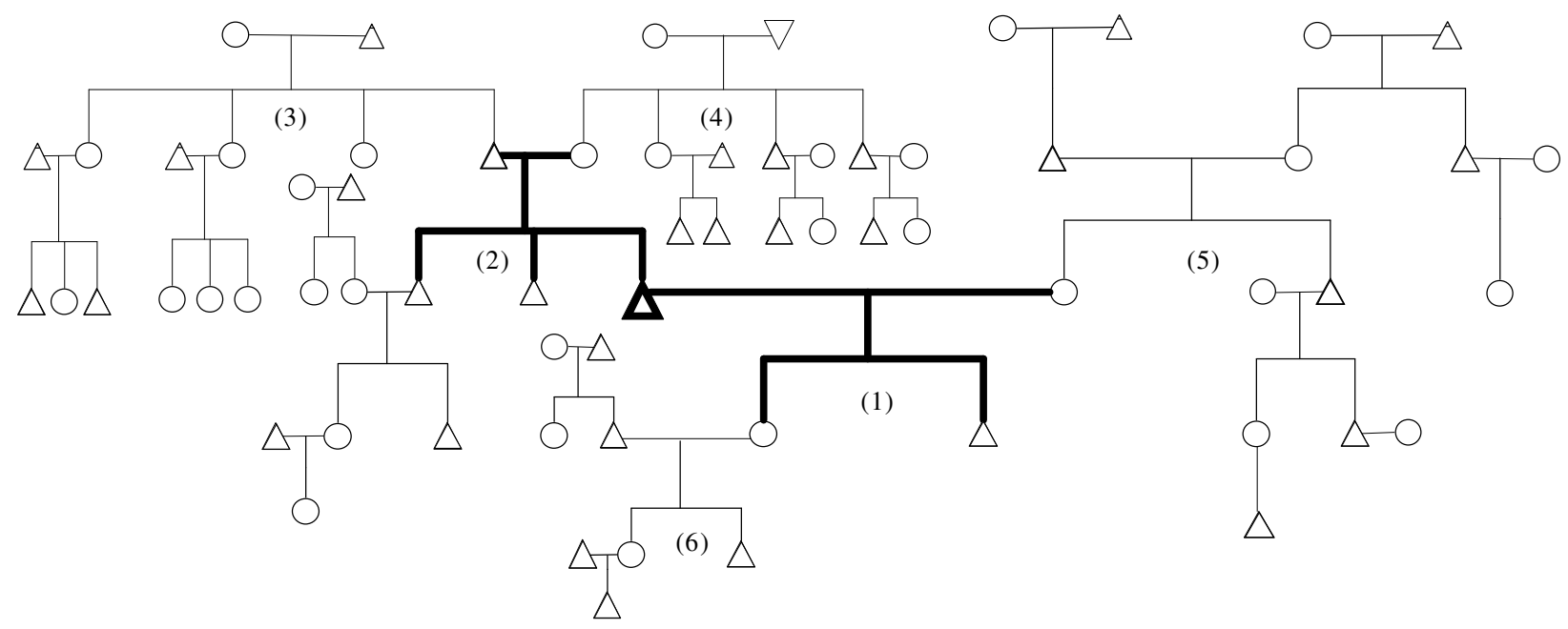

Figure 2: Birth Cohort Distribution by Country

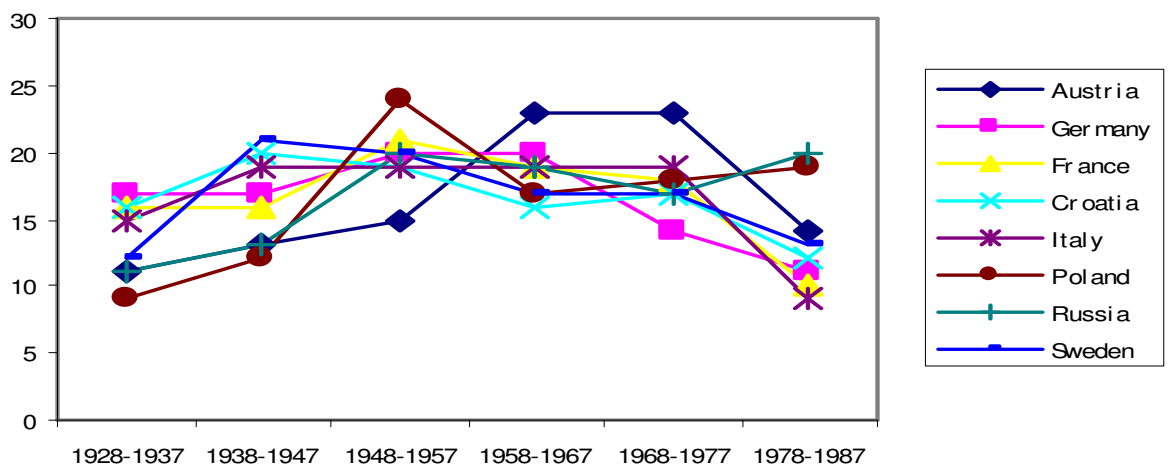

Figure 3: Mean Cumulative Cohort Fertility by Country

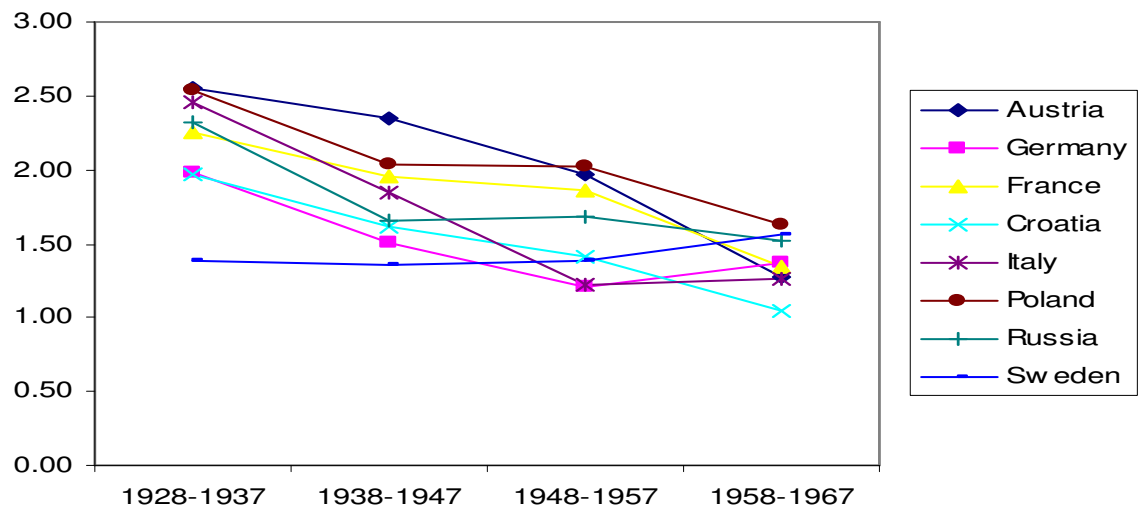


Table 4. Summary: Mean Cumulative Fertility by Birth Cohort and Country

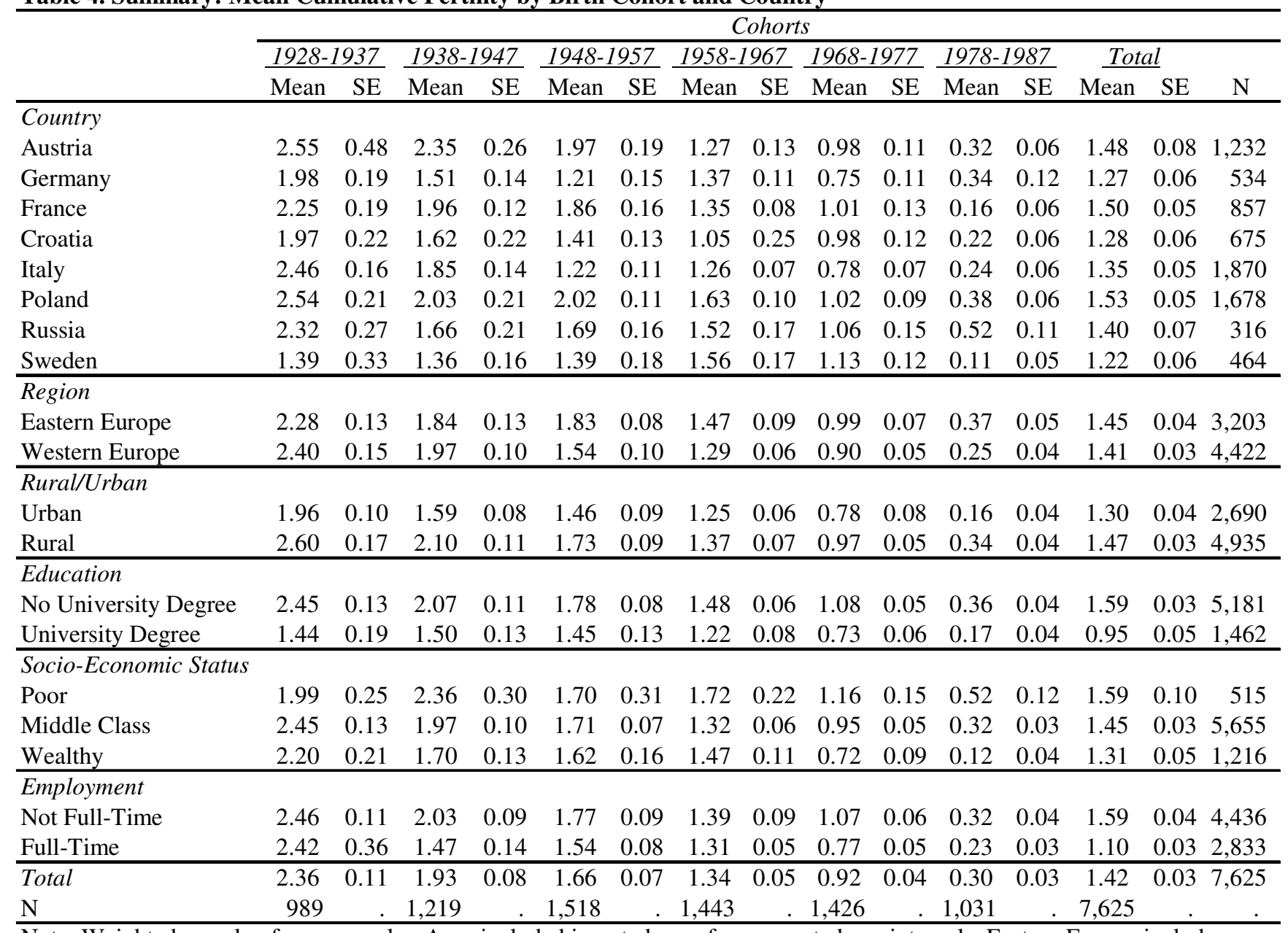

Note: Weighted sample of women only. Ages included imputed ages from reported age intervals. Eastern Europe includes

Germany, Croatia, Poland and Russia. Western Europe includes Austria, France, Italy and Sweden. 
Table 5. Cumulative Fertility: Results from Poisson Model (All Controls included)

\begin{tabular}{|c|c|c|c|c|c|}
\hline & Model 1 & Model 2 & Model 3 & Model 4 & Model 5 \\
\hline Austria (France) & $\begin{array}{c}0.261^{\text {**** }} \\
(0.059)\end{array}$ & $\begin{array}{l}0.134^{*} \\
(0.068)\end{array}$ & $\begin{array}{l}0.196^{* *} \\
(0.064)\end{array}$ & $\begin{array}{c}0.140 \\
(0.072)\end{array}$ & $\begin{array}{c}0.137 \\
(0.072)\end{array}$ \\
\hline Croatia & $\begin{array}{l}-0.072 \\
(0.077)\end{array}$ & $\begin{array}{l}-0.147 \\
(0.080)\end{array}$ & $\begin{array}{l}-0.129 \\
(0.080)\end{array}$ & $\begin{array}{l}-0.199^{*} \\
(0.085)\end{array}$ & $\begin{array}{l}-0.200^{*} \\
(0.085)\end{array}$ \\
\hline Germany & $\begin{array}{l}-0.213^{* *} \\
(0.067)\end{array}$ & $\begin{array}{c}-0.215^{* *} \\
(0.077)\end{array}$ & $\begin{array}{c}-0.192^{* *} \\
(0.073)\end{array}$ & $\begin{array}{l}-0.202^{*} \\
(0.080)\end{array}$ & $\begin{array}{l}-0.197^{*} \\
(0.081)\end{array}$ \\
\hline Italy & $\begin{array}{c}0.037 \\
(0.063)\end{array}$ & $\begin{array}{l}-0.015 \\
(0.069)\end{array}$ & $\begin{array}{c}0.002 \\
(0.067)\end{array}$ & $\begin{array}{l}-0.044 \\
(0.074)\end{array}$ & $\begin{array}{c}-0.045 \\
(0.073)\end{array}$ \\
\hline Poland & $\begin{array}{l}0.139^{*} \\
(0.057)\end{array}$ & $\begin{array}{c}0.019 \\
(0.066)\end{array}$ & $\begin{array}{c}0.084 \\
(0.062)\end{array}$ & $\begin{array}{c}0.048 \\
(0.071)\end{array}$ & $\begin{array}{c}0.049 \\
(0.072)\end{array}$ \\
\hline Russia & $\begin{array}{l}-0.150^{*} \\
(0.070)\end{array}$ & $\begin{array}{l}-0.197^{*} \\
(0.078)\end{array}$ & $\begin{array}{l}-0.144^{*} \\
(0.071)\end{array}$ & $\begin{array}{l}-0.195^{*} \\
(0.085)\end{array}$ & $\begin{array}{l}-0.193^{*} \\
(0.085)\end{array}$ \\
\hline Sweden & $\begin{array}{l}-0.178^{*} \\
(0.085)\end{array}$ & $\begin{array}{c}-0.253^{* *} \\
(0.097)\end{array}$ & $\begin{array}{l}-0.212^{*} \\
(0.090)\end{array}$ & $\begin{array}{l}-0.225 \\
(0.115)\end{array}$ & $\begin{array}{l}-0.227^{*} \\
(0.115)\end{array}$ \\
\hline Rural & & $\begin{array}{c}0.283^{* * *} \\
(0.033)\end{array}$ & & $\begin{array}{c}0.275^{* * *} \\
(0.036)\end{array}$ & $\begin{array}{c}0.275^{* * *} \\
(0.037)\end{array}$ \\
\hline Holds University Degree & & & $\begin{array}{c}-0.269^{* * *} \\
(0.038)\end{array}$ & $\begin{array}{l}-0.106^{*} \\
(0.043)\end{array}$ & $\begin{array}{l}-0.110^{*} \\
(0.044)\end{array}$ \\
\hline In Partnership & & & & $\begin{array}{c}0.293^{* * *} \\
(0.049)\end{array}$ & $\begin{array}{c}0.290^{* * * *} \\
(0.049)\end{array}$ \\
\hline Age & & & & $\begin{array}{l}-0.015^{*} \\
(0.008)\end{array}$ & $\begin{array}{c}-0.020 \\
(0.019)\end{array}$ \\
\hline Age Squared & & & & $\begin{array}{l}0.000^{* *} \\
(0.000)\end{array}$ & $\begin{array}{c}0.000 \\
(0.000)\end{array}$ \\
\hline Wealthy (Middle Class) & & & & $\begin{array}{c}-0.038 \\
(0.048)\end{array}$ & $\begin{array}{c}-0.034 \\
(0.049)\end{array}$ \\
\hline Poor & & & & $\begin{array}{c}0.018 \\
(0.069)\end{array}$ & $\begin{array}{c}0.021 \\
(0.070)\end{array}$ \\
\hline $1938-1947(1928-1937)$ & & & & & $\begin{array}{c}0.042 \\
(0.089)\end{array}$ \\
\hline $1948-1957$ & & & & & $\begin{array}{c}0.047 \\
(0.122)\end{array}$ \\
\hline $1958-1967$ & & & & & $\begin{array}{c}0.005 \\
(0.155)\end{array}$ \\
\hline $1968-1977$ & & & & & $\begin{array}{c}0.123 \\
(0.190)\end{array}$ \\
\hline $1978-1987$ & & & & & $\begin{array}{c}-0.121 \\
(0.274)\end{array}$ \\
\hline Constant & $\begin{array}{c}-2.569^{* * *} \\
(0.050)\end{array}$ & $\begin{array}{c}-2.699^{* * * *} \\
(0.073)\end{array}$ & $\begin{array}{c}-2.493^{* * *} \\
(0.056) \\
\end{array}$ & $\begin{array}{c}-2.781^{* * *} \\
(0.195) \\
\end{array}$ & $\begin{array}{c}-2.697^{* * * *} \\
(0.556)\end{array}$ \\
\hline Observations & 3,847 & 3,847 & 3,847 & 3,847 & 3,847 \\
\hline Log_Likelihood & $-1.6 e+08$ & $-1.6 e+08$ & $-1.6 e+08$ & $-1.5 e+08$ & $-1.5 e+08$ \\
\hline
\end{tabular}

Standard errors in parentheses

Note: Base category in parentheses. Weighted sample of women only.

Corrected estimates and robust standard errors account for between and within sample variation across multiply imputed datasets. Standard errors are also robust to clustering within kinships.

${ }^{*} p<0.05,{ }^{* * *} p<0.01,{ }^{* * *} p<0.001$ 
Figure 4: Cumulative Fertility and Select Covariates Across Cohorts (All Covariates Included)

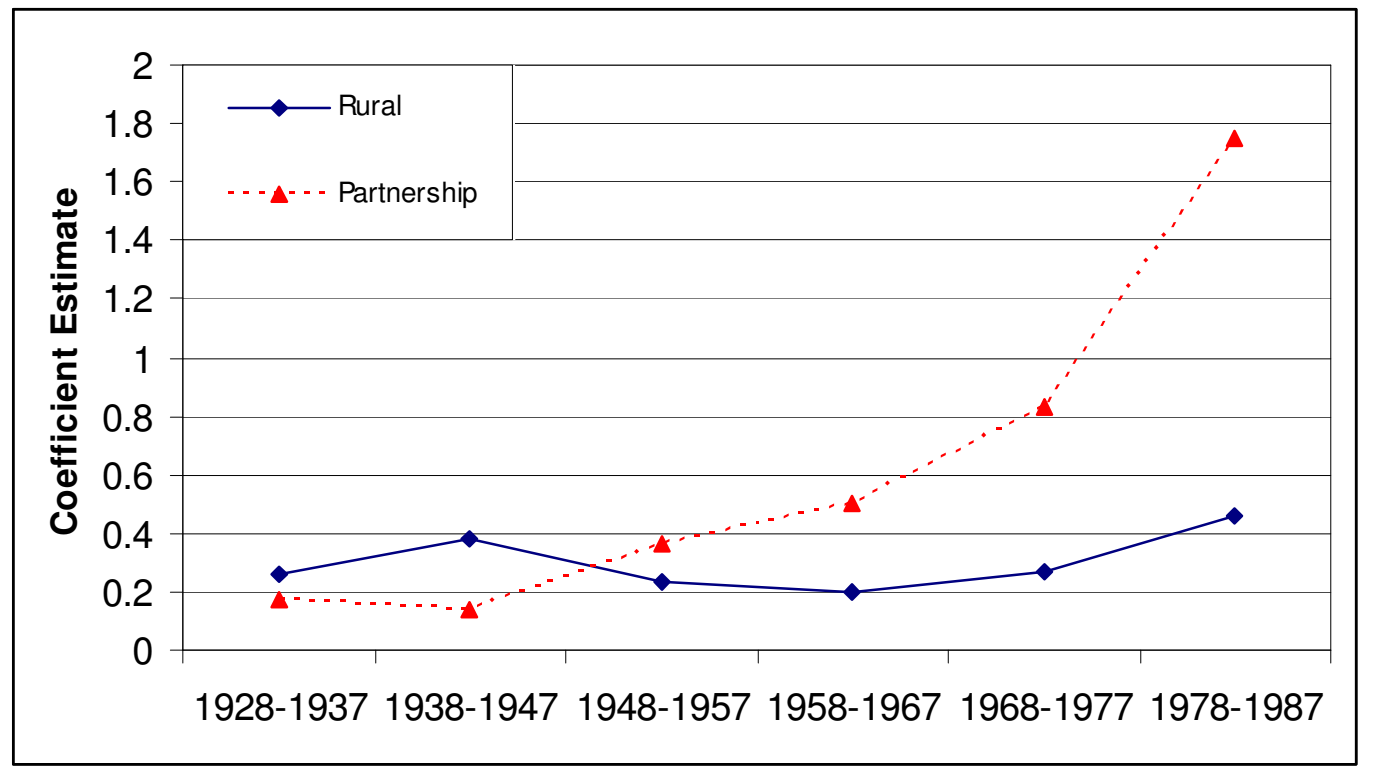

Figure 5: Mean Cohort Age at First Birth by Country

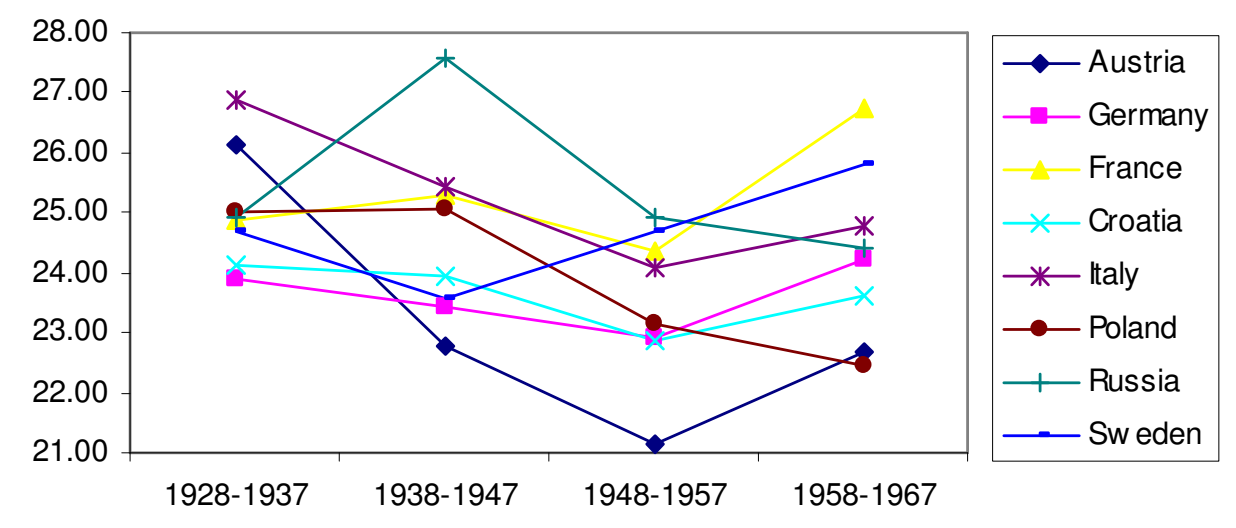


Table 6. Summary: Mean Age at First Birth by Birth Cohort and Country

\begin{tabular}{|c|c|c|c|c|c|c|c|c|c|c|c|c|c|c|c|}
\hline & \multicolumn{15}{|c|}{ Cohorts } \\
\hline & \multicolumn{2}{|c|}{$1928-1937$} & \multicolumn{2}{|c|}{$1938-1947$} & \multicolumn{2}{|c|}{$1948-1957$} & \multicolumn{2}{|c|}{$1958-1967$} & \multicolumn{2}{|c|}{$1968-1977$} & \multicolumn{2}{|c|}{$1978-1987$} & \multicolumn{2}{|c|}{ Total } & \multirow[b]{2}{*}{$\mathrm{N}$} \\
\hline & Mean & SE & Mean & SE & Mean & $\overline{S E}$ & Mean & SE & Mean & SE & Mean & SE & Mean & SE & \\
\hline \multicolumn{16}{|l|}{ Country } \\
\hline Austria & 26.14 & 0.79 & 22.79 & 0.63 & 21.12 & 0.64 & 22.69 & 0.55 & 23.34 & 0.60 & 21.21 & 1.31 & 23.02 & 0.28 & 1,232 \\
\hline Germany & 23.90 & 0.74 & 23.41 & 0.93 & 22.92 & 1.17 & 24.21 & 0.66 & 23.30 & 1.06 & 21.07 & 0.93 & 23.54 & 0.51 & 534 \\
\hline France & 24.89 & 0.74 & 25.30 & 0.85 & 24.38 & 0.68 & 26.74 & 0.79 & 26.45 & 0.60 & 21.11 & 0.69 & 25.25 & 0.44 & 857 \\
\hline Croatia & 24.14 & 0.70 & 23.94 & 0.69 & 22.88 & 0.45 & 23.60 & 0.78 & 23.92 & 0.74 & 20.18 & 1.25 & 23.66 & 0.33 & 675 \\
\hline Italy & 26.90 & 0.69 & 25.43 & 0.35 & 24.08 & 0.43 & 24.80 & 0.61 & 25.58 & 0.56 & 22.94 & 0.70 & 25.44 & 0.28 & 1,870 \\
\hline Poland & 25.01 & 1.02 & 25.08 & 0.63 & 23.16 & 0.34 & 22.47 & 0.47 & 23.37 & 0.53 & 20.76 & 0.50 & 23.54 & 0.30 & 1,678 \\
\hline Russia & 24.90 & 1.31 & 27.58 & 1.67 & 24.94 & 1.32 & 24.43 & 1.28 & 22.43 & 0.84 & 19.57 & 0.86 & 24.48 & 0.56 & 316 \\
\hline Sweden & 24.69 & 1.16 & 23.59 & 0.83 & 24.69 & 0.82 & 25.83 & 1.28 & 26.24 & 0.89 & 21.41 & 1.68 & 24.72 & 0.46 & 464 \\
\hline \multicolumn{16}{|l|}{ Region } \\
\hline Eastern Europe & 24.60 & 0.59 & 24.65 & 0.42 & 23.21 & 0.29 & 23.09 & 0.35 & 23.39 & 0.39 & 20.58 & 0.41 & 23.63 & 0.21 & 3,203 \\
\hline Western Europe & 26.32 & 0.46 & 24.52 & 0.33 & 23.22 & 0.35 & 24.35 & 0.39 & 24.80 & 0.40 & 22.15 & 0.65 & 24.61 & 0.20 & 4,422 \\
\hline \multicolumn{16}{|l|}{ Rural/Urban } \\
\hline Urban & 25.99 & 0.48 & 25.65 & 0.37 & 24.32 & 0.37 & 26.21 & 0.50 & 25.03 & 0.63 & 20.47 & 0.65 & 25.40 & 0.24 & 2,690 \\
\hline Rural & 25.62 & 0.50 & 24.06 & 0.33 & 22.82 & 0.28 & 23.06 & 0.29 & 24.14 & 0.34 & 21.43 & 0.45 & 23.79 & 0.18 & 4,935 \\
\hline \multicolumn{16}{|l|}{ Education } \\
\hline No University Degree & 25.38 & 0.37 & 24.07 & 0.29 & 22.82 & 0.24 & 23.29 & 0.29 & 23.57 & 0.31 & 21.00 & 0.46 & 23.80 & 0.15 & 5,181 \\
\hline University Degree & 28.54 & 1.23 & 26.51 & 0.56 & 26.14 & 0.60 & 26.67 & 0.56 & 26.78 & 0.50 & 22.29 & 0.74 & 26.41 & 0.28 & 1,462 \\
\hline \multicolumn{16}{|l|}{ Socio-Economic Status } \\
\hline Poor & 22.14 & 0.78 & 24.32 & 0.96 & 23.54 & 0.68 & 23.26 & 1.00 & 22.52 & 0.92 & 20.84 & 0.84 & 23.13 & 0.39 & 515 \\
\hline Middle Class & 25.90 & 0.40 & 24.46 & 0.28 & 22.91 & 0.27 & 23.81 & 0.31 & 24.34 & 0.32 & 21.28 & 0.46 & 24.17 & 0.17 & 5,655 \\
\hline Wealthy & 27.16 & 0.96 & 25.14 & 0.57 & 24.62 & 0.47 & 24.38 & 0.64 & 25.23 & 0.90 & 22.28 & 0.97 & 25.16 & 0.31 & 1,216 \\
\hline \multicolumn{16}{|l|}{ Employment } \\
\hline Not Full-Time & 25.96 & 0.38 & 24.32 & 0.28 & 22.41 & 0.27 & 23.49 & 0.37 & 24.33 & 0.41 & 21.51 & 0.51 & 24.18 & 0.17 & 4,436 \\
\hline Full-Time & 28.61 & 2.15 & 26.73 & 0.67 & 24.42 & 0.34 & 24.34 & 0.39 & 24.35 & 0.44 & 21.62 & 0.51 & 24.64 & 0.23 & 2,833 \\
\hline Total & 25.75 & 0.37 & 24.56 & 0.26 & 23.22 & 0.23 & 23.87 & 0.27 & 24.31 & 0.30 & 21.31 & 0.40 & 24.24 & 0.15 & 7,625 \\
\hline $\mathrm{N}$ & 989 & & 1,219 & & 1,518 & & 1,443 & & 1,426 & & 1,031 & & 7,625 & & \\
\hline
\end{tabular}

Note: Weighted sample of women only. Ages included imputed ages from reported age intervals. Eastern Europe includes

Germany, Croatia, Poland and Russia. Western Europe includes Austria, France, Italy and Sweden. 
Table 7. Estimated hazard ratios from Cox proportional hazards models of rate of transition to first birth

\begin{tabular}{|c|c|c|c|c|c|}
\hline & Model 1 & Model 2 & Model 3 & Model 4 & Model 5 \\
\hline \multirow[t]{2}{*}{ Austria (France) } & $1.294^{* * * *}$ & 1.123 & 1.156 & 1.095 & 1.102 \\
\hline & $(0.099)$ & $(0.087)$ & $(0.090)$ & $(0.087)$ & $(0.088)$ \\
\hline \multirow[t]{2}{*}{ Croatia } & 1.173 & 1.093 & 1.063 & 0.993 & 0.997 \\
\hline & $(0.096)$ & $(0.090)$ & $(0.089)$ & $(0.083)$ & $(0.085)$ \\
\hline \multirow[t]{2}{*}{ Germany } & 1.135 & 1.112 & 1.154 & 1.151 & 1.151 \\
\hline & $(0.105)$ & $(0.103)$ & $(0.109)$ & $(0.107)$ & $(0.109)$ \\
\hline \multirow[t]{2}{*}{ Italy } & 1.025 & 0.964 & 0.967 & 0.942 & 0.948 \\
\hline & $(0.066)$ & $(0.062)$ & $(0.064)$ & $(0.061)$ & $(0.062)$ \\
\hline \multirow[t]{2}{*}{ Poland } & $1.325^{\text {*** }}$ & $1.154^{*}$ & $1.207^{* *}$ & 1.141 & 1.133 \\
\hline & $(0.090)$ & $(0.080)$ & $(0.084)$ & $(0.081)$ & $(0.082)$ \\
\hline \multirow[t]{2}{*}{ Russia } & 1.066 & 0.992 & 1.041 & 0.988 & 0.993 \\
\hline & $(0.101)$ & $(0.097)$ & $(0.103)$ & $(0.102)$ & $(0.105)$ \\
\hline \multirow[t]{2}{*}{ Sweden } & 0.824 & $0.757^{* *}$ & $0.781^{*}$ & $0.805^{*}$ & 0.808 \\
\hline & $(0.087)$ & $(0.081)$ & $(0.084)$ & $(0.088)$ & $(0.089)$ \\
\hline \multirow{2}{*}{ Rural } & & $1.325^{\text {*** }}$ & & $1.240^{* * * *}$ & $1.242^{* * * *}$ \\
\hline & & $(0.054)$ & & $(0.053)$ & $(0.054)$ \\
\hline \multirow[t]{2}{*}{ Holds University Degree } & & & $0.666^{* * *}$ & $0.718^{* * *}$ & $0.719^{* * * *}$ \\
\hline & & & $(0.031)$ & $(0.037)$ & $(0.037)$ \\
\hline \multirow[t]{2}{*}{ In Partnership } & & & & $1.912^{* * *}$ & $1.921^{* * * *}$ \\
\hline & & & & $(0.130)$ & $(0.134)$ \\
\hline \multirow[t]{2}{*}{ Age } & & & & $1.055^{* * * *}$ & 1.027 \\
\hline & & & & $(0.011)$ & $(0.028)$ \\
\hline \multirow[t]{2}{*}{ Age Squared } & & & & $1.000^{* * *}$ & 1.000 \\
\hline & & & & $(0.000)$ & $(0.000)$ \\
\hline \multirow[t]{2}{*}{ Wealthy (Middle Class) } & & & & 0.923 & 0.918 \\
\hline & & & & $(0.049)$ & $(0.049)$ \\
\hline \multirow[t]{2}{*}{ Poor } & & & & 0.921 & 0.914 \\
\hline & & & & $(0.092)$ & $(0.094)$ \\
\hline \multirow[t]{2}{*}{$1938-1947$ (1928-1937) } & & & & & 0.944 \\
\hline & & & & & $(0.113)$ \\
\hline \multirow[t]{2}{*}{$1948-1957$} & & & & & 0.983 \\
\hline & & & & & $(0.170)$ \\
\hline \multirow[t]{2}{*}{$1958-1967$} & & & & & 0.824 \\
\hline & & & & & $(0.189)$ \\
\hline \multirow[t]{2}{*}{ 1968-1977 } & & & & & 0.712 \\
\hline & & & & & $(0.203)$ \\
\hline \multirow[t]{2}{*}{$1978-1987$} & & & & & 0.690 \\
\hline & & & & & $(0.257)$ \\
\hline Observations & 3,785 & 3,785 & 3,785 & 3,785 & 3,785 \\
\hline Log_Likelihood & -24105 & -24083 & -24071 & -23949 & -23945 \\
\hline
\end{tabular}

Exponentiated coefficients; Standard errors in parentheses

Note: Base category in parentheses. Weighted sample of women only.

Corrected estimates and robust standard errors account for between and within sample variation across multiply imputed datasets. Standard errors are also robust to clustering within kinships.

${ }^{*} p<0.05,{ }^{* *} p<0.01,{ }^{* * * *} p<0.001$ 
Figure 6: Entry into Adulthood and Select Covariates Across Cohorts (All Covariates Included)

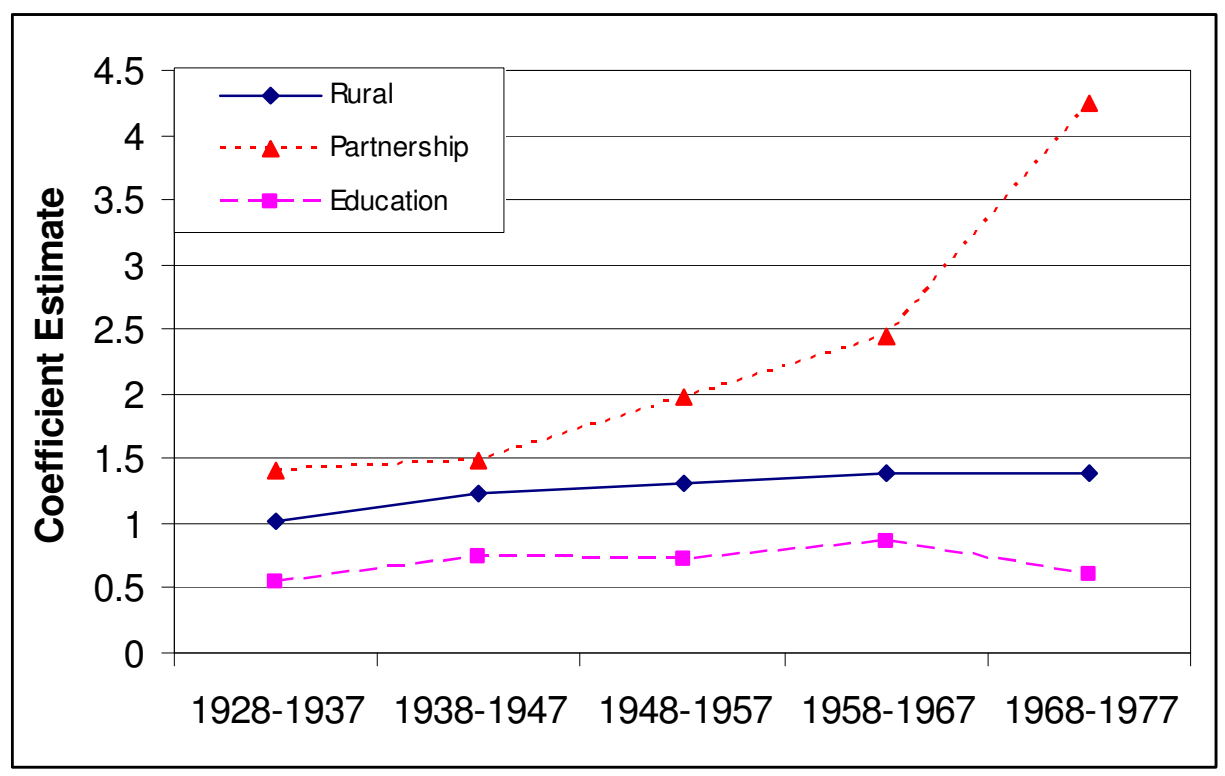

Table 8. Intergenerational Correlations: Mother and Daughter's Mean Cumulative Fertility

\begin{tabular}{lccc}
\hline & Correlation & p-value & $\mathrm{N}$ \\
\hline Country & & & \\
Austria & 0.20 & 0.00 & 962 \\
Germany & 0.14 & 0.01 & 350 \\
France & 0.09 & 0.03 & 630 \\
Croatia & 0.11 & 0.01 & 494 \\
Italy & 0.22 & 0.00 & 1,537 \\
Poland & 0.21 & 0.00 & 1,283 \\
Russia & 0.25 & 0.00 & 206 \\
Sweden & -0.06 & 0.27 & 313 \\
& & & \\
Cohort & & & \\
$1928-1937$ & 0.07 & 0.09 & 637 \\
1938-1947 & 0.11 & 0.00 & 860 \\
1948-1957 & 0.14 & 0.00 & 1,098 \\
1958-1967 & 0.13 & 0.00 & 1,134 \\
1968-1977 & 0.05 & 0.08 & 1,167 \\
1978-1987 & 0.12 & 0.00 & 880 \\
& & & \\
\hline Note: Weighted sample of women ages 18-80 only, sibships > 1. Ages included imputed \\
ages from reported age intervals. Correlations are averaged across multiple datasets.
\end{tabular}


Table 9. Siblings' Correlations: Sisters' and Siblings' Mean Cumulative Fertility

\begin{tabular}{lcccc}
\hline & $\begin{array}{c}\text { Sisters with } \\
\text { Siblings } \\
\text { Correlation }\end{array}$ & $\begin{array}{c}\text { Sisters with } \\
\text { Sisters } \\
\text { Correlation }\end{array}$ & $\begin{array}{c}\text { Sisters with } \\
\text { Brothers } \\
\text { Correlation }\end{array}$ & $\mathrm{N}$ \\
\cline { 2 - 5 } Auntry & & & & \\
Germany & 0.31 & 0.25 & 0.29 & 390 \\
France & 0.24 & 0.22 & 0.18 & 204 \\
Croatia & 0.31 & 0.39 & 0.16 & 286 \\
Italy & 0.20 & 0.17 & 0.16 & 239 \\
Poland & 0.42 & 0.34 & 0.40 & 546 \\
Russia & 0.36 & 0.34 & 0.23 & 554 \\
Sweden & 0.02 & 0.00 & 0.00 & 147 \\
Cohort & 0.21 & 0.15 & 0.20 & 211 \\
1928-1937 & & & & \\
1938-1947 & & 0.17 & 0.18 & 412 \\
1948-1957 & 0.19 & 0.20 & 0.27 & 493 \\
1958-1967 & 0.26 & 0.27 & 0.15 & 485 \\
1968-1977 & 0.23 & 0.29 & 0.16 & 358 \\
1978-1987 & 0.22 & 0.11 & 0.14 & 252 \\
& 0.17 & 0.19 & 0.16 & \\
\hline Note: Weighted sample of all women ages 18-80 only. Ages included imputed ages from reported age intervals. \\
Correlations are averaged across multiple datasets. & & &
\end{tabular}

Table 10. Cumulative Fertility and Sibship: Results from Poisson Model

\begin{tabular}{|c|c|c|c|c|}
\hline & Model 1 & Model 2 & Model 3 & Model 4 \\
\hline Sibship & $\begin{array}{l}0.078^{\text {*** }} \\
(0.011)\end{array}$ & $\begin{array}{c}0.078^{* * *} \\
(0.012)\end{array}$ & $\begin{array}{c}0.010 \\
(0.010)\end{array}$ & $\begin{array}{c}0.001 \\
(0.010)\end{array}$ \\
\hline Wealthy (Middle Class) & & $\begin{array}{l}-0.053 \\
(0.048)\end{array}$ & & $\begin{array}{l}-0.004 \\
(0.048)\end{array}$ \\
\hline Poor & & $\begin{array}{c}-0.009 \\
(0.127)\end{array}$ & & $\begin{array}{c}-0.103 \\
(0.117)\end{array}$ \\
\hline In Partnership & & & $\begin{array}{c}0.383^{* * *} \\
(0.085)\end{array}$ & $\begin{array}{l}0.414^{* * *} \\
(0.077)\end{array}$ \\
\hline
\end{tabular}

Notes: Standard errors in parentheses. Base category in parentheses. Weighted sample of women only. All models include full set of field site indicators. Corrected estimates and robust standard errors account for between and within sample variation across multiply imputed datasets. Standard errors are also robust to clustering within kinships.

${ }^{*} p<0.05,{ }^{* *} p<0.01,{ }^{* * *} p<0.001$ 
Table 11. Transition to First Birth and Sibling Age Differences: Estimated hazard ratios from Cox proportional hazard models.

\begin{tabular}{lccc}
\hline & Model 1 & Model 2 & Model 3 \\
\hline Age Interval Older Sibling & $1.019^{*}$ & $1.027^{* *}$ & $1.027^{* *}$ \\
& $(0.009)$ & $(0.009)$ & $(0.010)$ \\
Sibship & & 0.992 & 0.992 \\
& & $(0.016)$ & $(0.016)$ \\
& & Socio-Demg & Socio-Demg \\
& & Covariates & Covariates \\
& & & Cohort \\
& & & Indicators \\
& & & 1,717 \\
Observations & & $-8,939$ & $-8,937$ \\
\hline Log_Likelihood & $-9,058$ & & \\
\hline
\end{tabular}

Notes: Standard errors in parentheses. Weighted sample of women only. All models include full set of field site indicators. Socio-demographic covariates include: Partnership, Age, Age-squared, Rural, Education and socioeconomic status assessment. Corrected estimates and robust standard errors account for between and within sample variation across multiply imputed datasets. Standard errors are also robust to clustering within kinships. ${ }^{*} p<0.05,{ }^{* *} p<0.01,{ }^{* * *} p<0.001$

Table 12. Cumulative Fertility: Results from Poisson Model

\begin{tabular}{lcccc}
\hline & Model 1 & Model 2 & Model 3 & Model 4 \\
\hline Sibling Mean Cumulative Fertility & $0.099^{* * *}$ & $0.098^{* * *}$ & $0.085^{* *}$ & $0.085^{* *}$ \\
& $(0.027)$ & $(0.027)$ & $(0.028)$ & $(0.028)$ \\
Sibship & & 0.004 & -0.000 & 0.001 \\
& & $(0.011)$ & $(0.010)$ & $(0.010)$ \\
Age Interval with Older Sibling & & & 0.006
\end{tabular}

Socio-Demg Socio-Demg

Covariates Covariates

Observations
Standard errors in parentheses
Note: Base category in parentheses. Weighted sample of women only. All models include full set of field site
indicators. Socio-demographic covariates include: Partnership, Age, Age-squared, Rural, Education and
socioeconomic status assessment. Corrected estimates and robust standard errors account for between and within
sample variation across multiply imputed datasets. Standard errors are also robust to clustering within kinships.
${ }^{*} p<0.05,{ }^{* *} p<0.01,{ }^{* * *} p<0.001$


Table 13. Cumulative Fertility: Results from Poisson Model

\begin{tabular}{|c|c|c|c|c|c|}
\hline & Model 1 & Model 2 & Model 3 & Model 4 & Model 5 \\
\hline Sibling Mean Cumulative Fertility & $\begin{array}{l}0.104^{* *} \\
(0.036)\end{array}$ & & $\begin{array}{l}0.144^{* *} \\
(0.049)\end{array}$ & & $\begin{array}{c}0.061 \\
(0.048)\end{array}$ \\
\hline Brothers' Mean Cumulative Fertility & & $\begin{array}{c}0.049^{*} \\
(0.020)\end{array}$ & $\begin{array}{l}-0.041 \\
(0.030)\end{array}$ & & \\
\hline Sisters' Mean Cumulative Fertility & & & & $\begin{array}{l}0.074^{* *} \\
(0.026)\end{array}$ & $\begin{array}{c}0.039 \\
(0.034)\end{array}$ \\
\hline
\end{tabular}

\begin{tabular}{|c|c|c|c|c|c|}
\hline Observations & 1,031 & 1,031 & 1,031 & 1,031 & 1,031 \\
\hline
\end{tabular}

Standard errors in parentheses

Controls include Sibship and Age Differences and the full set of socio-demographic controls.

Note: Base category in parentheses. Weighted sample of women only. Corrected estimates and robust standard errors account for between and within sample variation across multiply imputed datasets. Standard errors are also robust to clustering within kinships.

${ }^{*} p<0.05,{ }^{* *} p<0.01,{ }^{* * * *} p<0.001$ 


\section{Appendix 1. Data}

\section{Predicting Missing Age Values}

Missing data in survey data raises important concerns about sample selection bias in model estimates. While these concerns are well known (see Rubin and Little (2002) and Daniels and Hogan (2008) for recent reviews) and are the subject of growing attention in demography (most recently, Jonker and van der Vaart 2007), they are often addressed in demography with an inadequate set of methods. We develop a set of procedures for handling missing reports of age in the KASS dataset in order to minimze potential sample selection bias and increase the precision of fertility estimates.

In the KASS dataset, individual age at the time of interview is defined with respondent reports of own birth year and the birth year for their kin members. Missing values in these reports occur for 35 percent of the full sample of men and women among the six birth cohorts from 1928 to 1978 . This rate of missingness becomes particularly pernicious given the importance of age for studying fertility timing. Any analysis of fertility timing is largely based on age differences between parents and their children. Moreover, the use of additional variables in this analysis which require the ages for pairs or groups of kin members exacerbates the implications of missing age reports. These variables include age at first birth, birth intervals and measures of the distributions of age related variables across kin members. The resulting reduction in sample size not only incurs a loss of precision for model estimates but also raises the possibility of sample selection bias. For these reasons, we adopt a set of procedures for predicting values for missing ages.

A set of methods for multiple imputation (Rubin 1976, 1987) is adopted to generate predicted values for missingness in age. A sequence of regressions is undertaken to incrementally identify the best model fits for predicting missing age values. This sequence involves estimating a set of generalized linear models for predicting missing age values. The KASS instrument and genealogical nature of the data provide ample information for generating predicted values for missing ages. The instrument includes questions soliciting not only specific ages, but also age intervals. When egos did not report the birth year, they were asked to specify 
the age interval which was most likely to contain the age of the referenced individual during the time of interview. Intervals distinguished ages 0-14, 15-24, 25-44, 45-64 and 65 and above. Age intervals may be used to constrain predicted values of ages and contribute to reducing much of the uncertainty in predicted outcomes. While it remains necessary to predict specific ages for missing age reports when age intervals are available, including age intervals contributes to reducing the rate of missingness to approximately 15 percent of the full sample. The genealogical structure of the KASS sample generates an additional set of rules that may also be used as constraints for predicted ages. For instance, missing ages for children and their parents may be constrained with respect to the age threshold of 15 years that is the convention for defining entry into risk for parenthood. The set of resulting rules contribute most to narrowing the bounds on predicted ages when individuals with missing ages have many siblings and children with reported ages.

The first step in this sequence of regressions is to estimate a model for individual age. Using the case complete data, observed age is modeled as a function of covariates including country, field site, sex, completed fertility, completed education, spouse's age, spouse's completed education, siblings' ages, parents' ages and children's ages. The estimated coefficients are used to predict precise ages for cases in which the birth year was reported missing. These predicted ages are constrained by the reported age intervals as well as a set of restrictions which are derived from family structure. Under the assumption that age and the chosen covariates are distributed according to a multivariate normal distribution, stochastic variation is then introduced to predicted ages. Such variation corresponds to the predicted error distribution and better approximates the within sample variance of predicted age.

Including covariates in models of age introduces the missingness in covariates into the predicted age values. For this reason, a second set of models are estimated in which each covariate with missingness is modeled as a function of the remaining covariates in the sample (van Buuren et al. 1999, Raghunathan et al. 2001). The updated sample including the predicted ages is used to predict one among the remaining covariates with missing data. This process is continued until all variables with missingness have predicted values. The set of covariates used in these models is not limited to the covariates used in the model for age. Variables are selected 
from among a large set of the socio-demographic measures available in the KASS data using standard model information criterion. These models include categorical and continuous variables and are estimated with appropriately specified models.

We account for uncertainty in the full set of estimated model coefficients that are used for predicting age by repeating these predictions multiple times and making draws from the posterior distribution of the parameters of all the underlying models. For each set of model estimates, the result is an iterative process between random draws of parameters (conditional on the data) and random draws of the missing data (conditional on parameters) (Rubin 1987). This iterative process continues until the values of parameters stabilize, reflecting convergence in the estimated set of model parameters (Tanner and Wong 1987). The entire procedure is repeated one thousand times to generate a single dataset with imputed age values. ${ }^{4}$

This set of procedures was repeated multiple times to generate additional datasets with imputed age values. Stability in the change in the variance of model estimates across these multiple datasets occurred by the tenth dataset. All analysis is undertaken with the resulting set of ten datasets. Consequently, descriptive statistics reflect sample statistics that are averaged across these multiple datasets. Variances for all statistics are corrected to account for both within sample and between sample variances across the ten datasets. Estimating models with these multiple datasets requires similar corrections for estimated coefficients and variances to account for the within and between sample variances. Although the full sample of kin is used in the multiple imputation and values are imputed for many covariates with missing values, only the imputed age values are included in the analytic sample. These values are also limited to cases where the age interval is observed. This amounts to 20 percent of the full sample of men and women and 16 percent of the analytic sample.

The multiple imputation approach has been shown to yield valid inferences when missing values occur with a sufficient degree of randomness. In this case, missingness is sufficiently random when the mechanisms which give rise to patterns of missingness depend neither on

\footnotetext{
${ }^{4}$ SAS version 9.1.3 was used to estimate all models and implement the full procedures in the multiple imputation.
} 
unobserved variables nor the unobserved values of observed variables (Rubin 1987). An analysis of predictors of missing age values identified a set of significant predictors that suggest that a sufficient share of the variation in the probability of missing age reports may be explained by the covariates included in the multiple imputation. These include sex, cohort, socioeconomic status and education. While there remains no definitive test for sufficient randomness in missing values, these results are consistent with a non-response mechanism that is missing at random and one which meets the assumptions for making valid inferences with multiple imputation.

\section{Sample Weights}

The sample weights adopted in the analysis are defined with respect to the unique nature of the population which is represented by the analytic sample. The analytic sample is defined by selecting all kin members within two or three degrees of relational distance from the survey respondent (described in section three). The resulting sample represents the population of individuals for each field site and their family members within these degrees of distance. The KASS sample was collected across the field sites with sampling frames which adopted households or individuals as the primary sampling units. Since the analytic sample in this chapter includes both survey respondents and selected kin members, it is suited for making inferences about the populations of individuals across the field sites and their family members. It is important to note that this population includes all kin members within three degrees of survey respondents who either co-reside in the respondents' households or live elsewhere.

The weights are the inverse of a probability of selection that is defined by the number of kinships sampled in the respondent's field site and the number of kin members who are within two or three degrees of relational distance to the respondent. By accounting for variation in both kinship sample sizes across the field sites and the number of each respondents' included kin members, the weights minimize sample selection bias in estimates of the effects of the aggregate measures of socio-demographic characteristics of included kin members. All statistics we present in the following adopt these weights and standard errors are robust to within kinship clustering. 